TITLE:

\title{
A novel saccharification method of starch using microwave irradiation with addition of activated carbon.
}

\section{AUTHOR(S):}

Matsumoto, Akikazu; Tsubaki, Shuntaro; Sakamoto, Masahiro; Azuma, Jun-ichi

\section{CITATION:}

Matsumoto, Akikazu ...[et al]. A novel saccharification method of starch using microwave irradiation with addition of activated carbon.. Bioresource technology 2011, 102(4): 39853988

\section{ISSUE DATE:}

2011-02

URL:

http://hdl.handle.net/2433/139469

\section{RIGHT:}

(C) 2010 Elsevier Ltd; This is not the published version. Please cite only the published version.; この論文は出版社版でありません。引用の際に は出版社版をご確認ご利用ください。 
1 A novel saccharification method of starch using microwave irradiation

\section{with addition of activated carbon}

Division of Environmental Science and Technology, Graduate school of Agriculture, Kyoto University, Kitashirakawa Oiwake-cho, Sakyo-ku, Kyoto 606-8502, Japan

*Corresponding author (Jun-ichi Azuma: telephone +81-75-753-6465, fax +81-75-753-6471, E-mail address: azumaji@kais.kyoto-u.ac.jp)

\section{ABSTRACT}

Activated carbons were investigated for their heat catalytic effects to improve saccharification of starch by autohydrolysis in water under microwave electromagnetic field, and the results were compared with graphite and carbon nanotubes. The activated carbons with low adsorptive capacity of maltose showed high saccharification rate, while those with high adsorptive capacity exhibited low saccharification. In addition, the former activated carbons decreased the saccharification temperature by $10-30{ }^{\circ} \mathrm{C}$. Maltooligosaccharides produced in the presence of the latter activated carbons were recovered by desorption with $50 \%$ aqueous ethanol. The results indicated that both adsorptive capacities of maltooligosaccharides and catalytic effects of hot spots arisen from the uneven surface structure of activated carbons might contribute to the improvement in starch saccharification. 
25 Keywords: microwave sensitizer, activated carbon, saccharification, starch, maltooligosaccharides

\section{Introduction}

Starch is an important product for food and chemical industries, and mostly produced from corn, wheat, potato and cassava. Starch is processed into maltooligosaccharides which are applied to viscosity improver, sweeteners, and so on (Nakakuki, 2003). Currently, bioethanol and biobased plastics such as polylactic acids are also produced from glucose obtained from starch (Lim et al., 2008). However, the competition between food and biorefined products discourages the use of starch as energy and materials. Alternatively, the by-products after starch production still retain residual starch as mixtures of polysaccharides with cell wall components leading to forthcoming demands for utilization of these polysaccharides (Yoshida et al., 2010).

Maltooligosaccharides are produced by enzymatic and acidic hydrolyses of starch. Microwave irradiation is an alternative method for hydrolysis of starch (Khan, et al., 1979, 1980; Yu et al., 1996; Rozzi and Singh 1999; Li et al., 2001; Warrand and Jansen 2007). Microwave is a kind of electromagnetic waves with frequencies between 300 $\mathrm{MHz}$ to $300 \mathrm{GHz}$ and has been used for telecommunication, radars, medical care as well as cooking method in domestic kitchens. Microwave-assisted organic and inorganic synthesis has been widely spread out due to the radical improvement in reaction rate and yield of the products. Irradiation of microwave also improves separation of chemical components from lignocelluloce for biorefineries (Tsubaki et al. 2008).

47 Solid catalyst-assisted microwave irradiation is a leading edge of this field since it does not emit hazardous acidic waste-liquid, and the catalysts are easily recovered 
49 (Zhang et al., 2009). In this paper we have investigated effect of activated carbon as a kind of non-toxic solid catalyst to improve the starch saccharification by microwave irradiation including the effect of graphite and carbon nanotubes.

\section{Materials and methods}

\subsection{Materials}

Corn, wheat and potato starches were supplied from Sanwa Cornstarch Co., Ltd., Wako Pure Chemical Industries, Ltd., and Matsutani Chemical Industry Co., Ltd., respectively. Activated carbons A, B and singlewall (diameter; below $2 \mathrm{~nm}$, length; 5-15 $\mu \mathrm{m})$ carbon nanotubes were purchased from Wako Pure Chemical Industries, Ltd. (Table 1). Activated carbons $\mathrm{C}$ and $\mathrm{E}$ were supplied from Ajinomoto Fine-Techno Co., Inc. Activated carbons D, F and graphite were obtained from Nacalai Tesque, Inc. Multiwall (diameter; below 2-15 nm, length; 1-10 $\mu \mathrm{m}$ ) carbon nanotube was supplied from Sigma-Aldrich Co. Nitric acid treated activated carbons were prepared by agitation of $20 \mathrm{~g}$ of activated carbons in $100 \mathrm{~mL}$ of $1 \mathrm{~N}$ nitric acid for $24 \mathrm{~h}$ at room temperature.

\subsection{Methods}

Microwave irradiation was performed by MicroSYNTH (Milestone Inc., $2.45 \mathrm{GHz}$, Max output $1,000 \mathrm{~W}$ ) which is a multimode microwave oven, and the real-time temperature inside the reactor was monitored by a thermocouple thermometer. The heating temperature was controlled by changing the microwave output through PID algorithm on a PC unit (easyWAVE 3 software, Milestone Inc.). One g of starch was suspended in $20 \mathrm{~mL}$ of distilled water in $100 \mathrm{~mL}$ reactor HPR-100 (Milestone Inc.) 
made of $\mathrm{TFM}^{\mathrm{TM}}$ [polytetrafluoroethylene (PTFE) containing very little $(<1 \%)$ perfluoropropyl vinyl ether (PPVE) modifier]. One g of activated carbons and graphite or $0.1 \mathrm{~g}$ of singlewall and multiwall nanotubes was separately added to the starch suspension as a kind of microwave sensitizer. Each starch suspension was microwaved at $180-230{ }^{\circ} \mathrm{C}$ for $2-22 \mathrm{~min}$ (including $2 \mathrm{~min}$ of come-up time to reach the desired temperatures) with stirring at $100 \mathrm{rpm}$ with a stirring rod. The saccharified fractions and activated carbons were separated by centrifugation after microwave irradiation. The recovered activated carbons were washed with water and the maltooligosaccharides adsorbed on the carbons were desorbed by elution with $50 \%$ aqueous ethanol.

The concentration of the glucose in the saccharified solution was determined by the mutarotase-GOD method by using Glucose C2 kit (Wako Pure Chemical Industries, Ltd.). Saccharification rate was determined as follows; starch carbons were measured by size-exclusion chromatography (SEC) equipped with MCIGEL CK-04SS column (7.5 mm $\times 200 \mathrm{~mm}$, Mitsubishi Chemical Co.) as described in the previous report (Yoshida et al., 2010).

BET surface area $\left(\mathrm{m}^{2} / \mathrm{g}\right)$ and t-plot micropore area $\left(\mathrm{m}^{2} / \mathrm{g}\right)$ were determined by ASAP 2020 (Micrometrics Co.) using $\mathrm{N}_{2}$ as adsorptive. The maltose absorptive rate (\%) was determined by the concentration ratio of free and adsorbed maltose after charge of maltose solution $(2.5 \%, \mathrm{w} / \mathrm{v})$ through small columns (diameter; $1 \mathrm{~cm})$ containing $2 \mathrm{~g}$ of activated carbons. Adsorbed maltose was recovered by elution with $50 \%$ aqueous ethanol and the concentrations of free and adsorbed maltose were determined by the 
97 phenol sulfuric acid. The amount of adsorbed maltose on the activated carbon was normalized by the total amount of maltose charged and described as maltose adsorptive rate. Microwave absorption capacity was evaluated by the increase in the highest temperature of the suspensions of activated carbons in water $(1 \mathrm{~g} / 12 \mathrm{~mL})$ at constant output of $100 \mathrm{~W}$ for $5 \mathrm{~min}$.

\section{Results and Discussion}

\subsection{Saccharification of three kinds of starches}

Microwave irradiation of corn, wheat and potato starches at $180-240{ }^{\circ} \mathrm{C}$ for $12 \mathrm{~min}$ produced glucose through autohydrolysis (Fig. 1A). The highest saccharification rate attained $69.4 \%$ from corn starch followed by potato starch $(56.8 \%)$ and wheat starch $(53.0 \%)$. The saccharification rates were higher than the previous results with shorter reaction time ( $\leq 24 \%$, Khan et al., 1979) because the present reaction temperature was higher by $20-30{ }^{\circ} \mathrm{C}$. Since corn starch was the most susceptible to microwave irradiation, the heating condition for saccharification of this starch was further optimized resulting in the maximal saccharification rate at $220^{\circ} \mathrm{C}$ for $12 \mathrm{~min}$ (Fig. 1B).

\subsection{Saccharification of corn starch with activated carbon}

Physical properties of the 6 activated carbons were summarized in Table 1. Activated carbons $\mathrm{B}, \mathrm{C}, \mathrm{D}$ and $\mathrm{F}$ showed lower adsorptive rate of maltose while activated carbons A and E showed higher adsorption capacity. Activated carbons have previously been utilized as microwave sensitizer for pyrolysis and degradation of hazardous compounds in dry state (Menéndez et al., 2010). The sensitizing effect of carbons used in this study was therefore evaluated by acceleration of heating temperature after $5 \mathrm{~min}$ of 
microwave irradiation with constant output at $100 \mathrm{~W}$. The microwave absorption capacity of the activated carbons (A-F) attained $111-118{ }^{\circ} \mathrm{C}$ which was $10 \%$ higher than the control (water; $102{ }^{\circ} \mathrm{C}$ ) verifying the microwave sensitizing effect of activated carbons suspended in water.

The effects of addition of activated carbons were summarized in Fig. 1C. The highest saccharification rate was achieved by activated carbon $\mathrm{B}\left(70.1 \%\right.$ at $\left.200{ }^{\circ} \mathrm{C}\right)$ followed by $\mathrm{C}\left(67.3 \%\right.$ at $\left.190^{\circ} \mathrm{C}\right)$ and $\mathrm{D}\left(63.9 \%\right.$ at $\left.210^{\circ} \mathrm{C}\right)$ for $12 \mathrm{~min}$ of heating time, respectively. In addition, reaction temperature of starch saccharification was considerably lowered (10 $30{ }^{\circ} \mathrm{C}$ ) by addition of these activated carbons. Although activated carbon $\mathrm{F}$ also improved the saccharification rate at lower temperatures below $200^{\circ} \mathrm{C}$, its maximum saccharification rate $(52.4 \%)$ was lower than the results obtained by the carbons B, C and D. The order of enhancement of saccharification rates was in good agreement with the adsorption capacity of maltose as shown in Table 1. These saccharification enhancing carbons had low adsorption capacity of maltose. On the other hand, activated carbons with high adsorption capacity of maltose (A and E) showed extremely low saccharification rate. To verify the importance of maltose adsorption capacity for saccharification, the activated carbons $\mathrm{B}$ and $\mathrm{C}$ were treated with nitric acid to improve the capacity. Nitric acid treatment increased the maltose adsorptive rates of B and C up to $58.8 \%$ and $52.2 \%$, resulting in decrease in saccharification rates to $46.2 \%$ and $36.1 \%$, respectively. This result confirmed that the adsorptive capacities of activated carbons were inversely related with the saccharification rate of starch. In addition, the other carbon materials, graphite and carbon nanotubes, which do not have any adsorptive capacity of maltooligosaccharides were also investigated as a control for their saccharification ability under microwave irradiation (Fig. 1D). Addition of graphite and 
singlewall and multiwall nanotubes showed saccharification rates up to $56.7 \%, 51.7 \%$ and $53.0 \%$, respectively, showing no positive effects on the saccharification of starch.

These results confirmed that the saccharification of starch has a clear inverse relationship with the degree of maltose adsorptive capacity in liquid phase (Table 1). In addition, they did not show any correlation with the $\mathrm{N}_{2}$ adsorptive properties such as BET surface area and t-plot micropore surface area because these values were determined under dry state.

The degrees of polymerization of maltooligosaccharides adsorbed on carbon materials were investigated by SEC. Activated carbons B, C, D and F showed only small peaks of glucose and maltose, while A and E showed consecutive peaks of maltooligosaccharides including maltose. These results suggested further that adsorptive capacity of maltooligosaccharides controls the degrees of saccharification of starch. Maltooligosaccharides trapped on the surface of the activated carbons survived against further degradation into glucose resulting in lower saccharification rate. Additionally, the decrease in the reaction temperature observed in B, C, D and F indicate operation of catalytic action of hot spots or sometimes called microplasmas on their surfaces (Zhang et al., 2007). Since activated carbons have uneven surfaces, some microscopic domains on the surface are considerably heated than surrounding area, producing hot spots and enforcing the reaction rate. Although these assumptions need further detailed elaborations, the difference in effects of activated carbons on saccharification of starch seems to be arisen from the balance of the adsorptive capacity of maltooligosaccharides including maltose and the production of hot spots depending the surface architecture of the activated carbons. 


\section{Conclusion}

Saccharification of starch was investigated under microwave irradiation in water with 6 activated carbons and 3 carbon materials. Only activated carbons with low adsorptive capacity of maltose accelerated the saccharification of starch leading to decrease in the optimal heating temperature by $10-30{ }^{\circ} \mathrm{C}$. Carbon materials without adsorbing capacity of maltose did not show the positive effects on saccharification. Although activated carbons having high adsorption capacity of maltose do not improve saccharification of starch, they can be utilized for production of maltooligosaccharides.

\section{References}

Khan, A.R., Johnson, J.A., Robinson, R.J., 1979. Degradation of starch polymers by microwave-energy. Cereal Chem. 56, 303-304.

Khan, A.R., Robinson, R.J., Johnson, J.A., 1980. Starch hydrolysis by acid and microwave energy. J. Food Sci. 45, 1449-1551.

Li, K.L., Xia, L.X., Li, J., Pang, J., Cao, G.Y., Xi, Z.W., 2001. Salt-assisted acid hydrolysis of starch to D-glucose under microwave irradiation. Carbohydr. Res. 331, 9-12.

Lim, L.-T., Auras, R., Rubino, M., 2008. Processing technologies for poly(lactic acid). Prog. Polym. Sci. 33, 820-852.

Menéndez, J.A., Arenillas, A., Fidalgo, B., Fernández, Y., Zubizarreta, L., Calvo, E.G., Bermúdez, J.M., 2010. Microwave heating processes involving carbon materials. Fuel Process. Technol. 91, 1-8.

Nakakuki, T., 2003. Development of functional oligosaccharides in Japan. Trends Glycosci. Glycotechnol. 15, 57-64. 
193 Rozzi, N.L., Singh, R.K., 2000. The effect of selected salts on the microwave heating of

194

195

196

197

198

199

200

201

202

203

204

205

206

207

208

209

210

211

212

213

214

215

216 starch solutions. J. Food Process. Preserv. 24, 265-273.

Tsubaki, S., Iida, H., Sakamoto, M., Azuma, J.I., 2008. Microwave heating of tea residue yields polysaccharides, polyphenols, and plant biopolyester. J. Agric. Food Chem. 56, 11293-11299.

Warrand, J., Janssen, H.G., 2007. Controlled production of oligosaccharides from amylose by acid-hydrolysis under microwave treatment: Comparison with conventional heating. Carbohydr. Polym. 69, 353-362.

Yoshida, T., Tsubaki, S., Teramoto, Y., Azuma, J., 2010. Optimization of microwave-assisted extraction of carbohydrates from industrial waste of corn starch production using response surface methodology. Bioresour. Technol. 101, 7820-7826.

Yu, H.M., Chen, S.T., Suree, P., Nuansri, R., Wang, K.T., 1996. Effect of microwave irradiation on acid-catalyzed hydrolysis of starch. J. Org. Chem. 61, 9608-9609.

Zhang, Z.H., Shan, Y.B., Wang, J., Ling, H.J., Zang, S.L., Gao, W., Zhao, Z., Zhang, H.C., 2007. Investigation on the rapid degradation of congo red catalyzed by activated carbon powder under microwave irradiation. J. Hazard. Mater. 147, $325-333$.

Zhang, Z.H., Zhao, Z.B.K. 2009. Solid acid and microwave-assisted hydrolysis of cellulose in ionic liquid. Carbohydr. Res. 344, 2069-2072.

\section{Figure Captions}

Fig. 1. Effects of microwave irradiation on saccharification of (A) 3 kinds of starches (heating time; $12 \mathrm{~min}$ ), (B) corn starch (heating time; 2-22 min), (C) corn starch with 
217 addition of 6 kinds of activated carbons (heating time; $12 \mathrm{~min}$ ) and (D) corn starch with 218 addition of graphite and nanotubes (heating time; $12 \mathrm{~min})$. The error bars show SD ( $n=$ $2193)$.

220 


\section{Table 1}

222 The raw materials and physical properties of 6 activated carbons.

\begin{tabular}{|c|c|c|c|c|c|c|}
\hline $\begin{array}{l}\text { Activated } \\
\text { carbon }\end{array}$ & Shape & $\begin{array}{c}\text { Raw } \\
\text { materials }\end{array}$ & $\begin{array}{c}\text { BET surface } \\
\text { area }\left(\mathrm{m}^{2} / \mathrm{g}\right)\end{array}$ & $\begin{array}{c}\mathrm{t} \text {-Plot } \\
\text { micropore } \\
\text { area }\left(\mathrm{m}^{2} / \mathrm{g}\right)\end{array}$ & $\begin{array}{l}\text { Maltose } \\
\text { adsorptive } \\
\text { rate }(\%)^{* *}\end{array}$ & $\begin{array}{c}\text { Highest } \\
\text { temperature } \\
\left({ }^{\circ} \mathrm{C}\right)^{*}\end{array}$ \\
\hline A & Powder & Sawdust & 1194 & 565 & $145.8 \pm 10.2$ & 113 \\
\hline B & Fractured & Sawdust & 1294 & 849 & $21.5 \pm 2.7$ & 113 \\
\hline $\mathrm{C}$ & Fractured & $\begin{array}{c}\text { Coconut } \\
\text { shell }\end{array}$ & 946 & 908 & $23.2 \pm 1.5$ & 112 \\
\hline $\mathrm{D}$ & Fractured & $\begin{array}{l}\text { Coconut } \\
\text { shell }\end{array}$ & 1042 & 964 & $28.6 \pm 8.2$ & 111 \\
\hline E & Fractured & $\begin{array}{l}\text { Bituminous } \\
\text { coal }\end{array}$ & 1886 & 1325 & $134.0 \pm 5.7$ & 115 \\
\hline $\mathrm{F}$ & Fractured & $\begin{array}{l}\text { Bituminous } \\
\text { coal }\end{array}$ & 1346 & 412 & $48.3 \pm 2.3$ & 118 \\
\hline
\end{tabular}

$224 * *$ Maltose adsorptive rate shows the amount of adsorbed maltose on the activated

225 carbon was normalized by the total amount of maltose charged (mean value $\pm \mathrm{SD}, n=$ $226 \quad 3)$ 

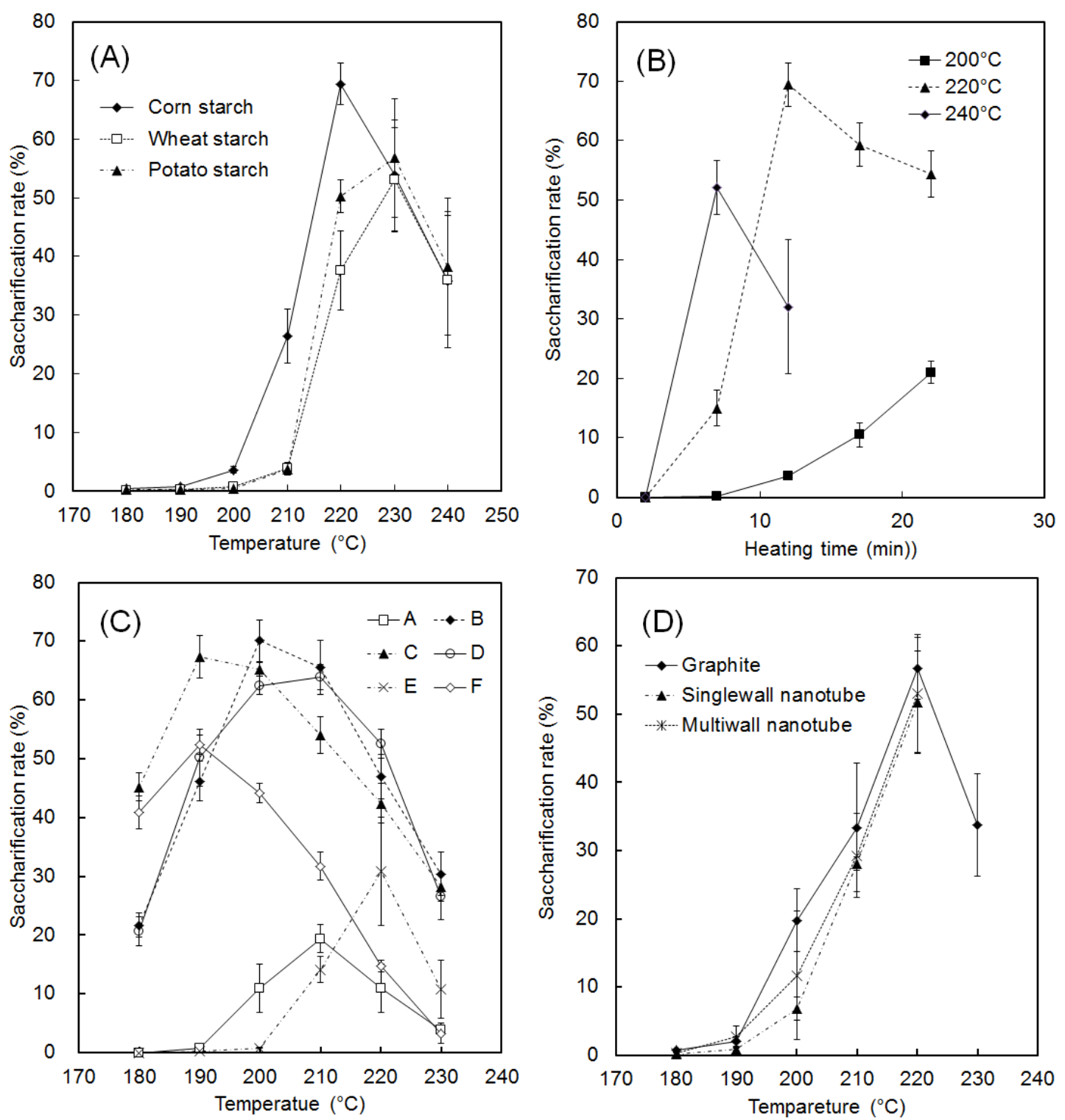

Fig. 1. Effects of microwave irradiation on saccharification of (A) 3 kinds of starches

230 (heating time; $12 \mathrm{~min}$ ), (B) corn starch (heating time; 2-22 min), (C) corn starch with

231 addition of 6 kinds of activated carbons (heating time; $12 \mathrm{~min}$ ) and (D) corn starch with 232 addition of graphite and nanotubes (heating time; $12 \mathrm{~min})$. The error bars show $\mathrm{SD}(n=$ $3)$. 